\title{
The p.G146A and p.P125P Polymorphisms in the Steroidogenic Factor-1 (SF-1) Gene Do Not Affect the Risk for Hypospadias in Caucasians
}

\author{
T. Adamovic ${ }^{a} \quad$ Y. Chen ${ }^{a, c}$ \\ H.T.T. Thai $^{\mathrm{a}} \quad$ X. Zhang ${ }^{\mathrm{a}, \mathrm{d}}$ \\ E. Markljung ${ }^{a}$ \\ S. Zhao ${ }^{\mathrm{e}}$
}

\section{A. Nordenskjölda, b}

\begin{abstract}
${ }^{a}$ Department of Women's and Children's Health and Center for Molecular Medicine, Karolinska Institutet and
bediatric Surgery, Astrid Lindgren Children Hospital, Karolinska University Hospital, Stockholm, Sweden;

'Minimally Invasive Urology Center, Provincial Hospital Affiliated to Shandong University, and

${ }^{d}$ Kidney Transplantation Center, and eDepartment of Urology, The Second Hospital, Shandong University, Jinan, China
\end{abstract}

\section{Key Words}

Hypospadias - Mutation analysis · NR5A1 - SNP · SF-1

\begin{abstract}
Hypospadias is a frequent congenital malformation in boys and is characterized by incomplete fusion of the urethral folds. The steroidogenic factor-1 (SF-1, NR5A1) gene plays a key role in hypothalamic-pituitary-steroidogenic organ development, and has previously been reported to be mutated in individuals with 46,XY disorder of sex development. Here, we investigated the role of SF-1 in hypospadias, a milder form of $46, \mathrm{XY}$ disorder of sex development. We performed direct sequencing analysis of the SF-1 gene in 2 male Caucasian twins exhibiting very severe hypospadias, and in 95 Caucasian boys with mild and severe hypospadias. We further extended the analysis by investigating 332 mild and severe hypospadias cases and 422 male controls using TaqMan assays. Our sequencing revealed a novel heterozygous p.R313H (c.938G >A) missense mutation in each twin, and no mutations in the 95 Caucasian cases. Instead, a missense p.G146A (c.437G >C), and a silent known p.P125P (c.375C >T) polymorphism, respectively, was found in several of the lat-
\end{abstract}

ter cases. Further investigation of the 2 polymorphisms in the larger material of cases and controls showed no significant genotypic or allelic association. In conclusion, the SF-1 gene may not play a significant role in the development of hypospadias in Caucasians.

Copyright $\odot 2012$ S. Karger AG, Basel

Hypospadias is characterized by incomplete fusion of the urethral folds in boys, and is one of the most common congenital malformations. The incidence of hypospadias in Sweden is 3 per 1,000 male births since the beginning of the 1970s according to the annual Swedish Malformation Registry (hypospadias rates worldwide are reviewed elsewhere [Fisch et al., 2010]). Furthermore, hypospadias is mainly a complex genetic disorder, and its development is most likely influenced by a combination of multiple genetic and environmental factors. During recent years, candidate genes such as the mastermind-like domain containing 1 (MAMLD1), activating transcription factor 3 (ATF3), zinc finger E-box-binding homeobox 1 (ZEB1) genes [Liu et al., 2005; Ogata et al., 2008; Qiao et al., 2011], among several others, have been implicated in the etiol-

\section{KARGER \\ Fax +4161306 1234 \\ E-Mail karger@karger.ch}

www.karger.com
(C) 2012 S. Karger AG, Basel

1661-5425/12/0066-0292\$38.00/0

Accessible online at:

www.karger.com/sxd
Dr. Tatjana Adamovic, $\mathrm{PhD}$

Department of Women's and Children's Health

Center for Molecular Medicine

CMM 02, Karolinska Institutet, SE-171 76 Stockholm (Sweden)

E-Mail tatjana.adamovic@ hotmail.com 
ogy of hypospadias. Still, most cases of hypospadias lack a molecular diagnosis.

Normal penile and urethral development begins in the sixth week of gestation with the formation of the urogenital sinus on the genital tubercle. The 2 edges of the urethral groove fuse in a proximal-to-distal direction, forming the urethra. Finally, the prepuce originates from the periphery of the glans penis and is complete by week 14 of fetal gestation. Variable loss-of-function changes of transcription factors, receptors, and enzyme pathways involved in Leydig cell development and androgen biosynthesis, may induce incomplete fusion of the urethral folds, and cause hypospadias [Wilhelm and Koopman, 2006].

The steroidogenic factor 1 (SF-1) gene, also known as adrenal 4-binding protein $(A D 4 B P)$ or nuclear receptor subfamily 5 group A number 1 (NR5A1), is located on the long arm of HSA9 (9q33) and consists of 7 exons. It codes for a 461 amino acid protein that shares structural homology with other members of the nuclear receptor superfamily [Wong et al., 1996]. This gene was initially suggested to play an important role in patients with primary adrenal failure, 46,XY gonadal dysgenesis and Müllerian structures, since similar phenotypes were detected in SF-1 knock-out mice by 3 independent groups [Luo et al., 1994; Sadovsky et al., 1995; Shinoda et al., 1995]. However, with time, these combined clinical features turned out to be rare in humans. In addition, only 3 SF-1 mutations were detected in these patients, suggesting a minor role of SF-1 in the investigated disease phenotypes [Achermann et al., 1999, 2002; Biason-Lauber and Schoenle, 2000]. The role of SF-1 in the embryo has further been reported to regulate the expression of enzymes involved in the steroidogenic system from week 8 of gestation, which results in masculinization of the external genitalia [Ikeda et al., 1994].

Furthermore, critical functional domains of SF-1 include an amino-terminal 2 zinc finger DNA-binding domain, an accessory DNA-binding region, a hinge region, and a ligand-binding domain (LBD) that forms an AF-2 structure, which regulate the transcription of a vast array of genes involved in adrenal and gonadal development, sex differentiation, steroidogenesis and reproduction by the hypothalamic-pituitary-adrenal/gonad axis [Morohashi et al., 1992]. Thus, relatively small changes of the SF-1 activity during the critical period in the embryo may cause a 'cascade reaction' in the endocrine system, which in turn may lead to clinically harmful effects.

Moreover, an increasing number of studies report variations and/or mutations in the $S F-1$ gene that may be associated with the etiology of the 46,XY disorder of sex development, severe hypospadias and other human reproductive phenotypes [Köhler et al., 2009]. In the present study, we intended to investigate the role of SF-1 in the disease of hypospadias in a Caucasian population.

\section{Materials and Methods}

\section{Direct Sequencing}

Two monozygotic Caucasian male twins with very severe hypospadias, to such a degree that a gender assignment was difficult, and their parents, in addition to a total of 95 Caucasian patients with hypospadias of different degrees (recruited at the Department of Pediatric Surgery) were selected for direct sequencing of the human SF-1 gene in exons and flanking regions. Both strands were investigated using Big Dye terminator sequencing (v3.1, Applied Biosystems) and the ABI3730 Sequencer (Applied Biosystems). Chromatograms were analyzed by SeqScape v2.7 (Applied Biosystems). PCR was carried out in a volume of $25 \mu \mathrm{l}$ containing DNA (100-500 $\mathrm{ng}), \mathrm{MgSO}_{4}(1.5 \mathrm{~mm})$, dNTP mixture (1.25 mM), Taq DNA polymerase $(2.5 \mathrm{U})$, and $0.2 \mu \mathrm{M}$ of each primer. The PCR program used for amplification was as follows: $95^{\circ} \mathrm{C}$ for $2 \mathrm{~min},\left(95^{\circ} \mathrm{C}\right.$ for $45 \mathrm{~s}$, $60^{\circ} \mathrm{C}$ for $30 \mathrm{~s}, 68^{\circ} \mathrm{C}$ for $\left.2 \mathrm{~min}\right) 35$ cycles. Primers were designed using the web-based Primer 3 program. The primer sequences are presented in online supplementary table 1 (for all online suppl. material, see (www.karger.com/doi/10.1159/000343782). Cycle sequencing extension products were created in a final volume of $20 \mu \mathrm{l}$ reaction using $12.5 \mu \mathrm{l} \mathrm{H} \mathrm{O}_{2}, 0.5 \mu \mathrm{l}$ forward or reverse primer at $10 \mu \mathrm{g} / \mathrm{ml}, 0.5 \mu \mathrm{l}$ template DNA, $4 \mu \mathrm{l}$ Big Dye Terminator Ready Reaction mix V1.1 (PE-ABI) and $2 \mu 15 \times$ Big Dye buffer. Cycle sequencing conditions consisted of an initial denaturation step at $96^{\circ} \mathrm{C}$ for 1 min followed by 25 cycles of $96^{\circ} \mathrm{C}$ for $10 \mathrm{~s}, 50^{\circ} \mathrm{C}$ for $5 \mathrm{~s}$ and $60^{\circ} \mathrm{C}$ for $4 \mathrm{~min}$. Unincorporated dye and other contaminants were removed with ethanol precipitation procedure.

\section{TaqMan and Statistical Analysis}

We next investigated a total of 332 Caucasian hypospadias cases consisting of 78 penoscrotal, scrotal and perineal cases, which we here defined as severe, and 254 glandular, coronal, mid and distal penile cases that belong to the mild group, using the TaqMan analysis. The control group consisted of 422 healthy voluntary male blood donors from the Karolinska University Hospital. We investigated the missense p.G146A (c.437G>C) and the silent p.P125P (c.375C >T) polymorphism, respectively, located in the SF-1 gene. Thus, polymorphism typing was performed using $5^{\prime}$ nuclease allele discrimination TaqMan assay together with fluorescent probes according to a standard protocol (Applied Biosystems). The results were analyzed on an ABI 7900HT. All statistical tests described below were performed by the PLINK program, version 1.07. Standard case/control allelic association test was performed, with missing data estimation. Odds ratio and its 95\% confidence interval were also calculated. Furthermore, the p value was single-step adjusted using the Bonferroni method. Values of $p<0.05$ (after adjustment with Bonferroni) were considered significant. Linkage disequilibrium of the 2 polymorphisms was further calculated. The Hardy-Weinberg test was also performed for each polymorphism. In addition, standard case/control genotypic association test was performed using Fisher's exact test. 
Table 1. Genotypic distribution of the missense p.G146A (c.437G>C) and the silent p.P125P (c.375C $>$ T) polymorphism in cases with mild and severe hypospadias, respectively, and in male controls

\begin{tabular}{|c|c|c|c|c|c|c|c|c|c|c|c|c|c|c|}
\hline & \multicolumn{7}{|c|}{ Genotype frequency of p.G146A, n } & \multicolumn{7}{|c|}{ Genotype frequency of p.P125P, n } \\
\hline & \multicolumn{2}{|l|}{$\mathrm{CC}$} & \multicolumn{2}{|l|}{ CG } & \multicolumn{2}{|l|}{ GG } & \multirow{2}{*}{$\begin{array}{l}\mathrm{p} \text { value } \\
\text { (unadjusted) }\end{array}$} & \multicolumn{2}{|l|}{ TT } & \multicolumn{2}{|l|}{ TC } & \multicolumn{2}{|l|}{$\mathrm{CC}$} & \multirow{2}{*}{$\begin{array}{l}\text { p value } \\
\text { (unadjusted) }\end{array}$} \\
\hline & cases & controls & cases & controls & cases & controls & & cases & controls & cases & controls & cases & controls & \\
\hline Mild form & 2 & 0 & 11 & 12 & 237 & 402 & 0.1212 & 0 & 0 & 1 & 1 & 251 & 416 & 1 \\
\hline Severe form & 0 & 0 & 3 & 12 & 75 & 401 & 0.717 & 0 & 0 & 1 & 1 & 77 & 416 & 0.2906 \\
\hline
\end{tabular}

Since hypospadias is considered to be a heterogeneous disease, the Caucasian cases were divided into 2 different groups, severe and mild, and accordingly analyzed.

Genomic DNA was extracted from either tissue harvested at surgery or from peripheral blood according to standard procedures reported elsewhere [Sambrook et al., 1989]. This study was approved by the ethics committee at Karolinska University Hospital. Informed written consent was obtained from all participants involved in the study.

\section{Results}

\section{Direct Sequencing Analysis}

Our initial direct sequencing analysis of the SF-1 gene in the germline DNA from the male monozygotic Caucasian twins exhibiting very severe hypospadias, revealed a novel heterozygous missense mutation in c.938G $>$ A, p.Arg313His. This mutation is located in the LBD. Upon further sequencing analysis of the DNA from the parents, the heterozygous mutation was also detected in the healthy father. To further explore the role of SF-1 in the disease of hypospadias, this time in a sample set consisting of patients with varying degrees of hypospadias (i.e. mild and severe cases), the entire gene was screened in 95 cases. The direct sequencing analysis of the extended sample set revealed that there were genomic variations in 2 known SNPs. Thus, we found a silent polymorphism, p.P125P (c.375G $>$ A) and a missense polymorphism, p.G146A (c.437G>C), respectively, in the hinge region of the SF-1 gene. Interestingly, 1 case with severe hypospadias was a double heterozygote, and 1 mild case was homozygous for the p.G146A and heterozygous for the p.P125P polymorphism, respectively.

\section{TaqMan Assay and Statistical Analysis, Respectively}

Since several cases in the extended sample set $(\mathrm{n}=95)$ displayed polymorphisms of the 2 known SNPs, we decided to further investigate the role of the p.P125P and p.G146A polymorphisms, respectively, in an even larger patient sample set. Thus, a total of 332 patients with mild and severe degrees of hypospadias were screened for the 2 polymorphisms using TaqMan assays. This experiment included the 95 patients screened with the direct sequencing methodology. In addition, 422 male controls were included in the analysis. We found the TaqMan experiment to fully conform to the sequencing analysis in the 95 cases included in both experiments, and the success rate for genotyping the markers was $98 \%$.

The TaqMan analysis revealed additional cases and controls, displaying a heterozygous or homozygous form of the 2 investigated SNPs in our large sample set, see table 1 . No additional double heterozygotes were detected. Furthermore, the case/control genotypic association test (using Fisher's exact test) revealed no significance for each individual polymorphism investigated in the mild and the severe hypospadias group, respectively (mild group: c.437G $>$ C (p.G146A), $\mathrm{p}=0.1212 ; \mathrm{c} .375 \mathrm{C}>\mathrm{T}$ (p.P125P), $\mathrm{p}=1$; severe group: c.437G $>$ C (p.G146A), $\mathrm{p}=$ 0.717 ; c.375C $>$ T (p.P125P), $p=0.2906$, table 1 ; both SNPs passed the Hardy-Weinberg test in the control group).

Moreover, the allelic association analysis of the 2 polymorphisms using PLINK did not show any significance in neither the mild nor severe hypospadias group ( $\mathrm{p}$ values after Bonferroni adjustment were all above 0.05 ), see table 2 . The p.G146A and p.P125P polymorphisms, respectively, locate $62 \mathrm{bp}$ away from each other, and were not in linkage disequilibrium $(\mathrm{R}-\mathrm{sq}=0.139)$.

\section{Discussion}

In the present study, we detected a novel heterozygous p.Arg313His (c.938G $>$ A) missense mutation located in the LBD of SF-1 in monozygotic male twins displaying very severe hypospadias. We further found no association between the p.G146A and p.P125P polymorphisms of the SF-1 gene and the disease of hypospadias in Caucasians. 
Table 2. Allelic prevalence and comparison of the $S F-1$ gene c.437G $>$ C (p.G146A) and the c.375C>T (p.P125P) polymorphism, respectively, in mild $(\mathrm{n}=254)$ and severe $(\mathrm{n}=78)$ hypospadias cases versus male controls $(\mathrm{n}=422)$

\begin{tabular}{|c|c|c|c|c|c|c|c|c|c|c|c|c|c|}
\hline CHR & Polymorphism & bp & A1 & F_A & F_U & A2 & CHISQ & $\mathrm{P}$ & OR & SE & L95 & U95 & BONF \\
\hline \multicolumn{14}{|c|}{ Mild cases versus controls } \\
\hline 9 & c. $437 \mathrm{G}>\mathrm{C}$ & 127262802 & $\mathrm{C}$ & 0.03 & 0.01453 & G & 3.738 & 0.05319 & 2.098 & 0.3915 & 0.9739 & 4.519 & 0.1064 \\
\hline 9 & c. $375 \mathrm{C}>\mathrm{T}$ & 127262864 & $\mathrm{~T}$ & 0.001984 & 0.001199 & $\mathrm{C}$ & 0.1297 & 0.7187 & 1.656 & 1.415 & 0.1034 & 26.53 & 1 \\
\hline \multicolumn{14}{|c|}{ Severe cases versus controls } \\
\hline 9 & c. $437 \mathrm{G}>\mathrm{C}$ & 127262802 & $\mathrm{C}$ & 0.01923 & 0.014 & G & 0.1929 & 0.6 & 1.33 & 0.6515 & 0.371 & 4.769 & 0.3667 \\
\hline 9 & c. $375 \mathrm{C}>\mathrm{T}$ & 127262864 & $\mathrm{~T}$ & 0.00641 & 0.001199 & $\mathrm{C}$ & 1.77 & 0.1834 & 5.374 & 1.417 & 0.3344 & 86.38 & 1 \\
\hline
\end{tabular}

$\mathrm{A} 1=$ Minor allele; $\mathrm{A} 2=$ major allele $\mathrm{CHR}=$ chromosome; $\mathrm{BONF}=\mathrm{p}$ value adjusted after the Bonferroni method; $\mathrm{bp}=\mathrm{base}$ pair; CHISQ $=\chi^{2}$ test $;$ F_A $=$ frequency for the minor allele in cases; F_U = frequency for the minor allele in controls; L95 = lower 95\% confidence interval $(\mathrm{CI})$ limit; $\mathrm{OR}=$ odds ratio; $\mathrm{P}=\mathrm{p}$ value; Polymorphism = single nucleotide polymorphism; $\mathrm{SE}=$ standard error; U95 = upper 95\% CI limit.

Table 3. Summary of results on the p.G146A polymorphism in different disorders and controls

\begin{tabular}{|c|c|c|c|c|c|c|c|c|c|c|c|}
\hline & \multicolumn{2}{|c|}{ Adrenal disorders } & \multicolumn{2}{|c|}{ Severe micropenis } & \multicolumn{2}{|c|}{ Type 2 diabetes } & \multicolumn{2}{|c|}{ Cryptorchism } & \multicolumn{3}{|c|}{ Hypospadias } \\
\hline $\mathrm{G} / \mathrm{C}$ & 10 & 5 & 15 & 24 & 64 & 55 & 34 & 35 & 11 & 3 & 12 \\
\hline C, \% & 30 & 8.2 & 31.7 & 17.4 & 37.1 & 27.3 & 29.2 & 18.8 & 3.0 & 1.9 & 1.4 \\
\hline Reference & \multicolumn{2}{|c|}{$\begin{array}{l}\text { Japanese individuals } \\
\text { investigated by } \\
\text { WuQiang et al. [2003] }\end{array}$} & \multicolumn{2}{|c|}{$\begin{array}{l}\text { Japanese individuals } \\
\text { investigated by } \\
\text { Wada et al. [2005] }\end{array}$} & \multicolumn{2}{|c|}{$\begin{array}{l}\text { Chinese Han individuals } \\
\text { investigated by } \\
\text { Liu et al. [2006] }\end{array}$} & \multicolumn{2}{|c|}{$\begin{array}{l}\text { Japanese individuals } \\
\text { investigated by } \\
\text { Wada et al. [2006] }\end{array}$} & \multicolumn{3}{|c|}{$\begin{array}{l}\text { Caucasians investigated in our } \\
\text { present study }\end{array}$} \\
\hline
\end{tabular}

Bold numbers indicate the percentage of controls exhibiting the G146A polymorphism.

Recent studies have reported heterozygous disruptive changes of the SF-1 gene in a range of 46,XY disorder of sex development phenotypes, such as severe undermasculinization, mild or partial gonadal dysgenesis, impaired androgen synthesis, although, with apparently normal adrenal function [Correa et al., 2004; Hasegawa et al., 2004; Mallet et al., 2004; Coutant et al., 2007; Lin et al., 2007; Reuter et al., 2007; Köhler et al., 2008]. SF-1 mutations have also been described in 46,XY adolescent females with primary amenorrhea and with low testosterone levels [Philibert et al., 2010]. Furthermore, Köhler et al. [2009] reported SF-1 mutations in 3 cases with severe hypospadias, but not in the milder form of hypospadias. To date, a total of 45 SF-1 mutations are reported in the Human Gene Mutation Database (http://www.hgmd. org/), and include missense/nonsense, splicing, small deletions/insertions/indels, gross deletions and complex rearrangements. In the current report, we present the iden- tification of a novel missense mutation (p.Arg313His) located in the LBD of SF-1 in 2 monozygotic male twins with very severe hypospadias. The mutation was also detected in the healthy father, although, since this specific mutation has previously not been reported, we hypothesized it may play a role in the development of hypospadias. In addition, quite recently, another study reported the identification of a novel p.Arg313Cys mutation in a patient with isolated distal hypospadias [Allali et al., 2011]. Moreover, several mutations in the LBD of SF-1 have been reported in other studies, including cases with severe hypospadias [Ferraz-de-Souza et al., 2011]. Thus, we sequenced the SF-1 gene in an extended Caucasian sample set, but found no further mutations. To clarify the role of the novel missense mutation (p.Arg313His) in the disease of hypospadias, additional studies are required.

The detected p.G146A polymorphism found in our extended sample set is located in the hinge region of SF-1 
and has previously been described to mildly diminish the transactivation activity of SF-1 [WuQiang et al., 2003]. The polymorphism has further been proposed to act as a susceptibility factor for adrenal disease, cryptorchidism, severe micropenis, and type 2 diabetes [WuQiang et al., 2003; Wada et al., 2005, 2006; Liu et al., 2006]. To provide an overview of the previously published data regarding the p.G146A polymorphism, we summarize these findings in table 3. Comparing previously published results with our data, we notice a rather high difference regarding how common the $\mathrm{C}$ allele is in the investigated control populations. According to our data, the $\mathrm{C}$ allele has a prevalence of $1.4 \%$ in the control population, whereas the frequency of the same allele is approximately 5-18 fold increased in other control populations. This may be explained by ethnic group differences or simply by the insufficient number of individuals investigated in each study. Nevertheless, in all the published studies referred to in table 3 , the $\mathrm{C}$ allele was found to be associated with an increased risk of the investigated diseases. In our present study, we show that the $\mathrm{C}$ allele is not associated with the disease of hypospadias in Caucasians.

In conclusion, we have investigated the largest Caucasian cohorts of control and hypospadias cases with regard to the SF-1 gene. Based on our data, we show that the p.G146A and p.P125P polymorphisms of the $S F-1$ gene do not play an important role in the development of hypospadias with varying degrees in the investigated Caucasian population. To clarify the role of the novel missense mutation (p.Arg313His) in the disease of hypospadias, additional studies are required.

\section{Acknowledgements}

The authors acknowledge the Swedish Research Council, the Foundation Frimurarna and Her Royal Highness Crownprincess Lovisa's Foundation in Sweden.

\section{References}

Achermann JC, Ito M, Hindmarsh PC, Jameson JL: A mutation in the gene encoding steroidogenic factor-1 causes XY sex reversal and adrenal failure in humans. Nat Genet 22: 125-126 (1999).

-Achermann JC, Ozisik G, Ito M, Orun UA, Harmanci $\mathrm{K}$, et al: Gonadal determination and adrenal development are regulated by the orphan nuclear receptor steroidogenic factor-1, in a dose-dependent manner. J Clin Endocrinol Metab 87:1829-1833 (2002).

Allali S, Muller J, Brauner R, Lourenco D, Boudjenah $\mathrm{R}$, et al: Mutation analysis of NR5A1 encoding steroidogenic factor 1 in $77 \mathrm{pa}$ tients with 46, XY disorders of sex development (DSD) including hypospadias. PLoS ONE 6:24117 (2011)

-Biason-Lauber A, Schoenle EJ: Apparently normal ovarian differentiation in a prepubertal girl with transcriptionally inactive steroidogenic factor 1 (NR5A1/SF-1) and adrenocortical insufficiency. Am J Hum Genet 67: 1563-1568 (2000).

Correa RV, Domenice S, Bingham NC, Billerbeck AE, Rainey WE, et al: A microdeletion in the ligand binding domain of human steroidogenic factor-1 causes XY sex reversal without adrenal insufficiency. J Clin Endocrinol Metab 89:1767-1772 (2004).

Coutant R, Mallet D, Lahlou N, Bouhours-Nout $\mathrm{N}$, Guichet A, et al: Heterozygous mutation of steroidogenic factor- 1 in $46, \mathrm{XY}$ subjects may mimic partial androgen insensitivity syndrome. J Clin Endocrinol Metab 92: 2868-2873 (2007).
Ferraz-de-Souza B, Lin L, Achermann JC: Steroidogenic factor-1 (SF-1, NR5A1) and human disease. Mol Cell Endocrinol 336:198205 (2011).

Fisch H, Hyun G, Hensle TW: Rising hypospadias rates: disproving a myth. J Pediatr Urol 6:37-39 (2010).

Hasegawa T, Fukami M, Sato N, Katsumata N, Sasaki G, et al: Testicular dysgenesis without adrenal insufficiency in a $46, \mathrm{XY}$ patient with a heterozygous inactive mutation of steroidogenic factor-1. J Clin Endocrinol Metab 89:5930-5931 (2004).

Ikeda Y, Shen WH, Ingraham HA, Parker KL: Developmental expression of mouse steroidogenic factor-1, an essential regulator of the steroid hydroxylases. Mol Endocrinol 8: 654-662 (1994).

Köhler B, Lin L, Ferraz-de-Souza B, Wieacker P, Heidemann P, Schröder V, et al: Five novel mutations in steroidogenic factor 1 (SF1, NR5A1) in 46,XY patients with severe underandrogenization but without adrenal insufficiency. Hum Mutat 29:59-64 (2008).

Köhler B, Lin L, Mazen I, Cetindag C, Biebermann $\mathrm{H}$, et al: The spectrum of phenotypes associated with mutations in steroidogenic factor 1 (SF-1, NR5A1, Ad4BP) includes severe penoscrotal hypospadias in $46, \mathrm{XY}$ males without adrenal insufficiency. Eur J Endocrinol 161:237-242 (2009).
- Lin L, Philibert P, Ferraz-de-Souza B, Kelberman D, Homfray T: Heterozygous missense mutations in steroidogenic factor 1 (SF1) $A d 4 B P, N R 5 A 1)$ are associated with 46,XY disorders of sex development with normal adrenal function. J Endocrinol Metab 92: 991-999 (2007).

Liu B, Wang Z, Lin G, Agras K, Ebbers M, et al: Activating transcription factor 3 is up-regulated in patients with hypospadias. Pediatr Res 58:1280-1283 (2005).

Liu W, Liu M, Fan W, Nawata H, Yanase T: The Gly146Ala variation in human SF-1 gene: its association with insulin resistance and type 2 diabetes in Chinese. Diabet Res Clin Pract 73:322-328 (2006).

Luo X, Ikeda Y, Parker KL: A cell-specific nuclear receptor is essential for adrenal and gonadal development and sexual differentiation. Cell 77:481-490 (1994).

-Mallet D, Bretones P, Michel-Calemard L, Dijoud F, David M, et al: Gonadal dysgenesis without adrenal insufficiency in a 46, XY patient heterozygous for the nonsense C16X mutation: a case of SF1 haploinsufficiency. J Clin Endocrinol Metab 89:4829-4832 (2004).

Morohashi K, Honda S, Inomata Y, Handa H, Omura T: A common trans-acting factor, Ad4-binding protein, to the promotors of steroidogenic P-450s. J Biol Chem 267: 17913-17919 (1992). 
Ogata T, Wada Y, Fukami M: MAMLD1 (CXorf6): a new gene for hypospadias. Sexual development: genetics, molecular biology, evolution, endocrinology, embryology, and pathology of sex determination and differentiation. Sex Dev 2:244-250 (2008).

- Philibert P, Leprieur E, Zenaty D, Thibaud E, Polak M, et al: Steroidogenic factor-1 (SF-1) gene mutation as a frequent cause of primary amenorrhea in 46,XY female adolescents with low testosterone concentration. Reprod Biol Endocrinol 19:28 (2010).

Qiao L, Tasian GE, Zhang H, Cunha GR, Baskin $\mathrm{L}$ : ZEB1 is estrogen responsive in vitro in human foreskin cells and is overexpressed in penile skin in patients with severe hypospadias. J Urol 185:1888-1893 (2011).

- Reuter AL, Goji K, Bingham NC, Matsuo M, Parker KL: A novel mutation in the accessory DNA-binding domain of human steroidogenic factor 1 causes XY gonadal dysgenesis without adrenal insufficiency. Eur J Endocrinol 157:233-238 (2007)
Sadovsky Y, Crawford PA, Woodson KG, Polish JA, Clements MA, et al: Mice deficient in the orphan receptor stereoidogenic factor 1 lack adrenal glands and gonads but express $\mathrm{P} 450$ side-chain-cleavage enzyme in the placenta and have normal embryonic serum levels of corticosteroids. Proc Natl Acad Sci USA 92: 10939-10943 (1995).

Sambrook J, Fritsch E, Maniatis T: Isolation of high-molecular-weight DNA from mammalian cells, in Sambrook J, Russell DW (eds): Molecular Cloning, pp 14-23 (Cold Spring Harbour Lab Press, New York 1989).

Shinoda K, Lei H, Yoshii H, Nomura M, Nagano $\mathrm{M}$, et al: Developmental defects of the ventromedial hypothalamic nucleus and pituitary gonadotroph in the Ftz-F1 disrupted mice. Dev Dyn 204:22-29 (1995).
Wada Y, Okada M, Hasegawa T, Ogata T: Association of severe micropenis with Gly146Ala polymorphism in the gene for steroidogenic factor-1. Endocr J 52:445-448 (2005).

-Wada Y, Okada M, Fukami M, Sasagawa I, Ogata T: Association of cryptorchidism with Gly146Ala polymorphism in the gene for steroidogenic factor-1. Fertil Steril 85:787-790 (2006).

Wilhelm D, Koopman P: The makings of maleness: towards an integrated view of male sexual development. Nat Rev Genet 7:620-631 (2006).

Wong M, Ramaya MS, Chrousos GP, Driggers $\mathrm{PH}, \mathrm{Parker} \mathrm{KL}$ : Cloning and sequence analysis of the human gene steroidogenic factor 1 . J Mol Endocrinol 17:139-147 (1996).

-WuQiang F, Yanase T, Wei L, Oba K, Nomura M, et al: Functional characterization of a new human Ad4BP/SF-1 variation, G146A. Biochem Biophys Res Commun 311:987-994 (2003). 